\title{
Grid-Connected Emergency Back-Up Power Supply
}

\author{
Dhiman Chowdhury'1, Mohammad Sharif Miah², Md. F. Hossain² \\ ${ }^{1}$ Department of Electrical Engineering, University of South Carolina, Columbia, SC, USA \\ ${ }^{2}$ Department of Electrical and Electronics Engineering, Daffodil International University, Dhaka, Bangladesh \\ Email:dhiman@email.sc.edu, sharifdiu68@gmail.com, ferozhossain.eee@gmail.com
}

How to cite this paper: Chowdhury, D., Miah, M.S. and Hossain, Md.F. (2019) Grid-Connected Emergency Back-Up Power Supply. Circuits and Systems, 10, 1-19. https://doi.org/10.4236/cs.2019.101001

Received: December 1, 2018

Accepted: January 28, 2019

Published: January 31, 2019

Copyright $\odot 2019$ by author(s) and Scientific Research Publishing Inc. This work is licensed under the Creative Commons Attribution International License (CC BY 4.0).

http://creativecommons.org/licenses/by/4.0/

\begin{abstract}
This paper documents design and modeling of a grid-connected emergency back-up power supply for medium power applications. Back-up power supplies are very important in regard to support electrical loads in the events of grid power outage. However, grid-integration of a back-up power supply substantiates continual power transfer to the loads, especially to the critical loads, which should not suffer from power interruptions. Therefore, design and circuit modeling of switching converters based reliable grid-tied emergency back-up power supply are presented in this paper. There are a rectifier-link boost derived battery charging circuit and a 4-switch push-pull power inverter circuit which are controlled by high frequency pulse width modulation (PWM) signals. This paper presents a state averaging model and Laplace domain transfer function of the charging circuit and a switching converter model of the power inverter circuit. A changeover relay based transfer switch controls the power flow towards the utility loads. During off-grid situations, loads are fed power by the proposed inverter circuit and during on-grid situations, battery is charged by an ac-link rectifier-fed boost converter. However, there is a relay switching circuit to control the charging phenomenon of the battery. The proposed design is simulated in PLECS and the simulation results corroborate the reliability of the presented framework.
\end{abstract}

\section{Keywords}

Back-Up Power Supply, Laplace Domain, Push-Pull Inverter, State Averaging Model, Switching Converter Model

\section{Introduction}

Power electronic converters can provide alternate and sustainable solutions to grid power failure, poor voltage regulation and inefficient and expensive mains 
power supply systems. In the events of grid power unavailability, emergency utility loads and critical loads like computers and different medical devices can be supplied power by power electronic devices, like instant power supply (IPS) and uninterruptible power supply (UPS). However, in both IPS and UPS systems, power inverter circuits are designed to efficaciously deliver power to the utility loads. The basic difference between IPS and UPS is the back-up power switching transfer time.

In this paper, a medium power grid-connected switching converters based emergency back-up power supply is presented, which can be used as a reliable UPS or IPS or both the systems. There is a 4-switch push-pull inverter circuit which supports the utility loads when the mains power is unavailable. The battery is charged by a rectifier-link dc-dc boost converter circuit. There is electrical isolation at the source-end of the battery charger which steps-down the line voltage and the converter produces a suitable voltage level to charge the battery. The switching phenomenon of the boost converter is controlled by high frequency $(40 \mathrm{kHz})$ pulse width modulation (PWM) signals to reduce the current ripples, size of the filter components and switching losses. The converter is designed in such a manner that it operates in continuous conduction mode (CCM) so that the steady state inductor current is greater than the ripple components and never reaches to zero or being negative during the converter operation.

A 4-switch push-pull inverter circuit yields to large current driving capabilities to deliver sufficient power to the loads. There are parallel snubber components with the inverter switches to reduce $\frac{\mathrm{d} v}{\mathrm{~d} t}$ effects. There is a $50 \mathrm{~Hz}$ center-tapped step-up transformer, which is followed by an L-C low pass filter at the load side. The inverter switches are controlled by two complementary PWM signals of the mains line frequency $(50 \mathrm{~Hz})$.

During an on-grid condition, the loads and the battery are fed power by the mains line and the grid-tied charger respectively. During an off-grid condition, the customized power supply system delivers power to the loads. The power transfer switching from grid to the customized power supply system is automatic and instantaneous. The transfer application is substantiated by a changeover relay with a switch operating rate of $3-5 \mathrm{~ms}$. There is a switching relay circuit to control the charging process of the battery. If the battery voltage is at its rated value, the charge controller disconnects the battery from the charger and thus prevents the over-charging phenomenon.

For effective and sustainable power supply solutions, a number of novel PWM inverter topologies are reported in [1] [2] [3] [4] [5]. A $250 \mathrm{~W}$ soft-switching current-fed push-pull converter topology is articulated in [6]. For a single-phase PWM inverter, a current quality evaluation methodology is presented in [7]. For performance betterment, reliable PWM control techniques for inverter circuits are proposed in [8] and [9]. The proposed push-pull inverter based emergency power supply system can be used as a UPS device to support critical loads. Several inverter topologies and modeling approaches for UPS applications are pro- 
posed in [10] [11] [12]. Immaculate parallel UPS operations and control techniques of single phase inverters for UPS systems are documented in [13] [14] [15]. However, designs, models and applications of different switching power electronic converters are presented in [16]-[21]. The power inverter topologies reported in [1]-[15] require sophisticated design methodologies and intricate control mechanisms, whereas the proposed back-up power supply consists of comparatively simple circuit topologies and switch control mechanisms. The switching signals are generated using analog circuits designed for particular frequencies. However, the circuit models derived in this paper explains the operation of the constituent converters. Besides being an efficient power supply solution, the proposed design is considered to be very reasonable for consumer applications.

In this paper, a state averaging model of the battery charging circuit is derived and a Laplace domain transfer function is determined from the equivalent time domain model. The inverter circuit is analyzed in the form of an equivalent switching converter model. The proposed system is simulated in PLECS (version 4.2) for an R-L load. However, harmonic analysis of the mains current, inverter output voltage and load current are conducted to evaluate the corresponding total harmonic distortion (THD) values. The sending-end power factor is measured as well to verify the reliability of the proposed system. From simulations the obtained results are as follows: sending-end power factor is 0.96 , mains current THD is $20.88 \%$, inverter output voltage THD is $15.02 \%$ and load current THD is 14.98\% approximately for an R-L load of about $104 \mathrm{~W}$ (maximum).

Section 2 presents the description of the proposed design. Section 3 describes the state space model of the battery charging circuit. Section 4 describes the switching converter model of the power inverter. Section 5 documents the simulation results and finally, Section 6 concludes the paper.

\section{Proposed Design}

A grid-integrated emergency back-up power supply with automatic transfer switching application between the mains power and customized power inverter circuit is presented in this paper. A 4-switch push-pull inverter circuit with snubber components and an iron-core step-up output transformer is designed to support loads in the absence of grid power. A rectifier-fed boost converter is developed to charge the battery at a suitable voltage level. Figure 1 presents the proposed system layout.

The transfer switching operation from the mains line to the customized power circuit in case of grid power failure is implemented by a changeover relay following a double pole double throw (DPDT) switching structure. Direct connection relay $C R_{1}$ is the relay terminal connected to the mains power and it bridges the connection between the grid and utility load. Circuit-to-load connection relay $\mathrm{CR}_{2}$ is the relay terminal connected to the inverter output and it bridges the connection between the customized power supply unit and utility 


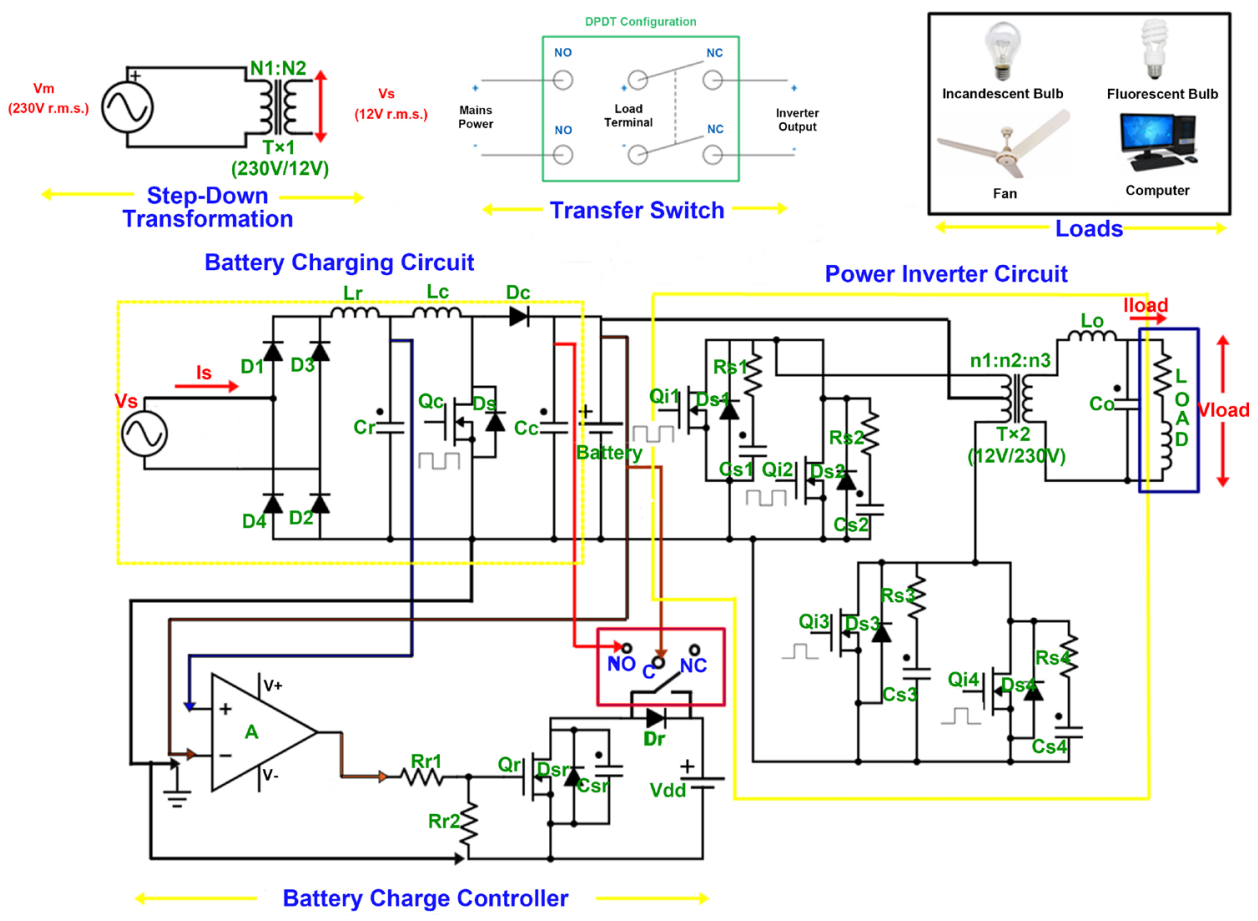

Figure 1. Proposed system layout of the grid-connected emergency back-up power supply

load. $C R_{1}$ and $C R_{2}$ get activated alternatively and in general case, $C R_{2}$ operates when the mains power is unavailable. A generic relay has two switching terminals and one moving pole to switch from one terminal to another. In this DPDT relay, the normally closed $(N C)$ terminal or $C R_{2}$ is connected to the inverter output and the normally open $(N O)$ terminal or $C R_{1}$ is connected to the mains line. The moving pole is connected to the load. In the de-energized state, which means the off-state of the mains power, the load is connected to $N C$ and conversely, in the energized state, which means the on-state of the mains power, the load gets automatically connected to $N O$.

An intelligible relay switching circuit is designed, which determines the connectivity of the battery to the charger. If the battery voltage is at its rated nominal value, the switching circuit disconnects the charger from the battery to provide over-voltage and over-heat protection. Charger connection relay $C C R$ is basically a single pole double throw (SPDT) relay switching circuit to connect the battery terminal to the charger. Battery charge controller consists of an op-amp based comparator circuit, in which the reference voltage $V_{\text {ref }}$ is fed from the rectifier output and it is connected to a non-inverted port. The battery voltage $V_{b a t}$ is connected to an inverted port of the op-amp. The difference voltage $V_{\text {diff }}$ is $\left[V_{\text {ref }}-V_{\text {bat }}\right]$ and the comparator output voltage $V_{\text {comp }}$ is $-V_{\text {sat }}=V-$, if $V_{\text {bat }} \geq V_{\text {ref }}$ and is $+V_{\text {sat }}=V+$, if $V_{\text {bat }}<V_{\text {ref }}$; here $V_{\text {sat }}$ is the saturation voltage. The comparator circuit is followed by a relay switching circuit of which the input is the comparator output voltage. Here NO terminal is connected to the charger, $N C$ terminal is open and the moving pole, $C$ is connected to the battery. When $V_{\text {comp }}=V-$, there is no current flow through the switching 
relay and the battery is disconnected from the charger terminal. When $V_{\text {comp }}=V+$, a current flows through the relay to close the switch and the battery is connected to the charger.

The switching operations of the boost converter and push-pull inverter can be executed by PWM signals of $40 \mathrm{kHz}$ and $50 \mathrm{~Hz}$ respectively. Analog integrated chip (IC) SG3525A can be used to generate the switch-control PWM signals. SG3525A generally produces two complementary pulses of the same frequency. In case of the boost converter, any of the two generated $40 \mathrm{kHz}$ pulses can be used to control the switching operation. In regard to maintaining the trade-off between switching loss and conduction loss of a switching device, $40 \mathrm{kHz}$ switching frequency is optimized here. In case of the push-pull inverter, both of the $50 \mathrm{~Hz}$ pulses are used to control the switching operations of the inverter legs, leg1: $Q_{i 1}-Q_{i 2}$ and leg2: $Q_{i 3}-Q_{i 4}$. Figure 2 and Figure 3 present the designs of $40 \mathrm{kHz}$ and $50 \mathrm{~Hz}$ PWM signal generation circuits respectively.

\section{State Averaging Model of the Proposed Battery Charging Circuit}

The state space averaging technique implies an approximation methodology to analyze switching converters being operated with high switching frequencies. The state space modeling yields to a continuous-time signal frequency analysis and results in a non-linear system though the original circuit is a linear system. However, with small signal approximations, state space modeling provides good stability and time variant behavioral analysis of switching converters. The generic state space model equations are

$$
\begin{aligned}
& \dot{\boldsymbol{x}}(t)=A \boldsymbol{x}(t)+B \boldsymbol{u}(t) \\
& \boldsymbol{y}(t)=C \boldsymbol{x}(t)+D \boldsymbol{u}(t)
\end{aligned}
$$

here $\boldsymbol{x}(t)$ is the vector of state variables to be analyzed (inductor current and capacitor voltage), $\dot{\boldsymbol{x}}(t)=\frac{\mathrm{d} \boldsymbol{x}(t)}{\mathrm{d} t}, \boldsymbol{u}(t)$ is the input source vector (voltage or current source), $\boldsymbol{y}(t)$ is the output vector (output voltage) and $A, B, C$ and $D$ are constant matrices. Laplace transformations of the state equations yield to transfer function of a circuit system, which is a good determinant of the input-output relationship. Corresponding Laplace domain transformations of (1a) and (1b) to get the system transfer function are

$$
\begin{gathered}
S \boldsymbol{X}(S)=A \boldsymbol{X}(S)+B \boldsymbol{U}(S) \\
\boldsymbol{X}(S)=\left[(S I-A)^{-1} B\right] \boldsymbol{U}(S) \\
\boldsymbol{Y}(S)=C \boldsymbol{X}(S)+D \boldsymbol{U}(S) \\
\boldsymbol{Y}(S)=\left[C(S I-A)^{-1} B+D\right] \boldsymbol{U}(S) \\
G(S)=\frac{\boldsymbol{Y}(S)}{\boldsymbol{U}(S)}=\left[C(S I-A)^{-1} B+D\right]
\end{gathered}
$$




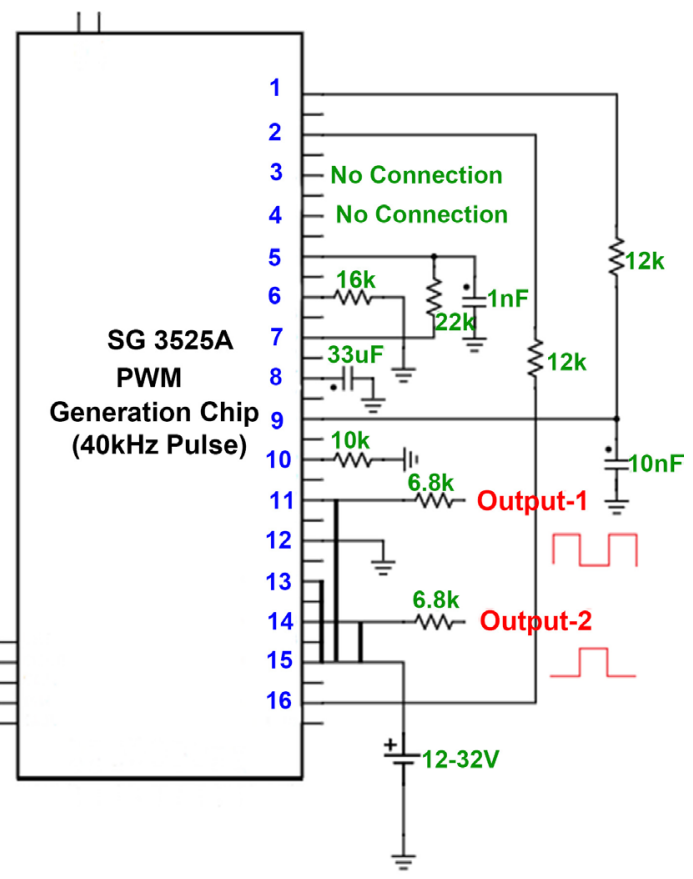

Figure 2. $40 \mathrm{kHz}$ PWM signal generation circuit using SG3525A.

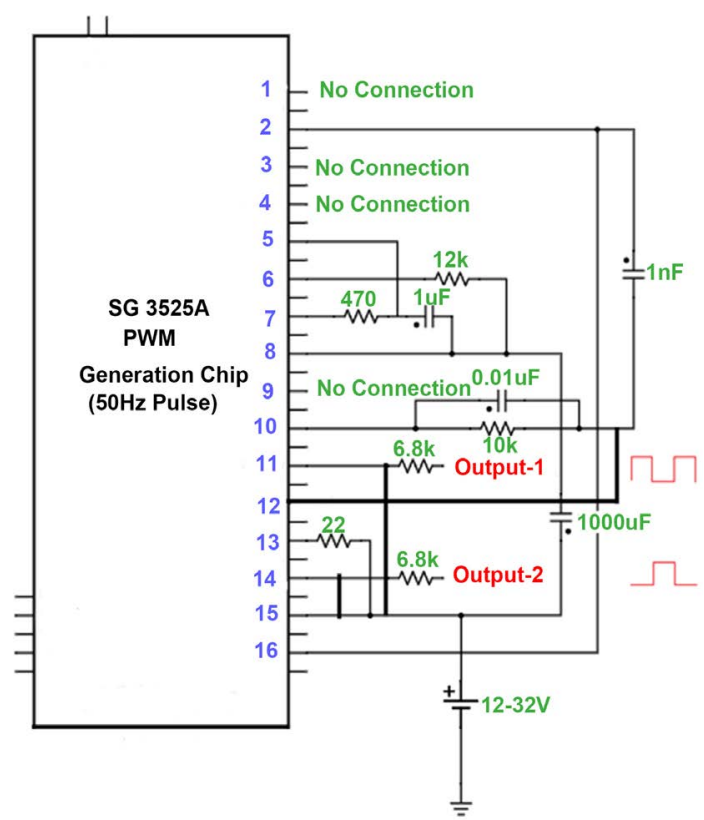

Figure 3. $50 \mathrm{~Hz}$ PWM signal generation circuit using SG3525A.

here $I$ is an $m \times n$ identity matrix, $\boldsymbol{X}(S), \boldsymbol{U}(S)$ and $\boldsymbol{Y}(S)$ are the s-domain transformations of $\boldsymbol{x}(t), \boldsymbol{u}(t)$ and $\boldsymbol{y}(t)$ respectively. $G(S)$ is the system transfer function. Figure 4 presents the overall state space configuration and transfer function model of the battery charger in which the system transfer function can be expressed as 


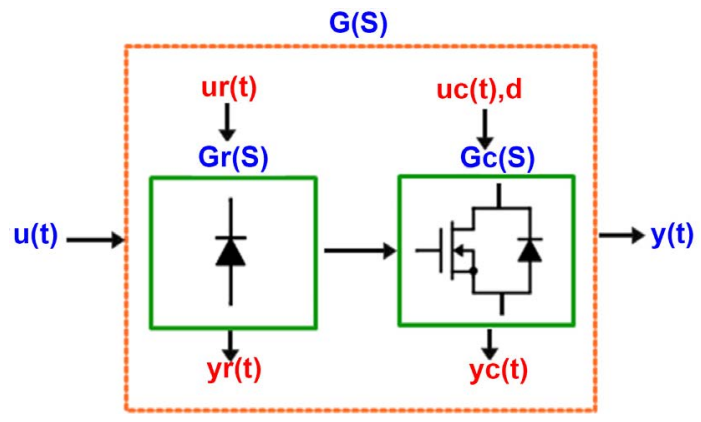

Figure 4. State space structure and transfer function model of the battery charging circuit (two series blocks, $G_{r}(S)$ and $G_{c}(S)$, denote s-domain transfer functions of the rectifier and boost converter respectively).

$$
G(S)=G_{r}(S) G_{c}(S)
$$

here $G_{r}(S)$ and $G_{c}(S)$ are the transfer functions of the rectifier and boost converter circuits respectively. To reduce redundancy of terminology, any time domain variable, $m(t)$, is denoted as $m$ in further expressions in this paper.

\subsection{Derivation of $G_{r}(S)$}

Figure 5 presents the equivalent state space model of the rectifier circuit where $u_{r}$ is the input ac voltage (stepped-down), $y_{r}$ is the output voltage, $x_{r 1}$ and $x_{r 2}$ are the state variables. $S_{r 1}, S_{r 2}, S_{r 3}$ and $S_{r 4}$ are the state space models of $D_{1}, D_{2}, D_{3}$ and $D_{4}$ respectively. The rectifier circuit can be analyzed separately during two half (positive and negative) cycles of the input source such that

$$
u_{r}=u_{r+}+u_{r-}
$$

During the positive (+ve) half cycle of the input

$$
\begin{gathered}
\dot{x}_{r 1}=-\frac{1}{L_{r}} x_{r 2}+\frac{1}{L_{r}} u_{r+}, \dot{x}_{r 2}=\frac{1}{C_{r}} x_{r 1}, y_{r+}=x_{r 2} \\
A_{r 1}=\left[\begin{array}{cc}
0 & -\frac{1}{L_{r}} \\
\frac{1}{C_{r}} & 0
\end{array}\right] \\
B_{r 1}=\left[\begin{array}{c}
\frac{1}{L_{r}} \\
0
\end{array}\right], C_{r 1}=\left[\begin{array}{ll}
0 & 1
\end{array}\right], D_{r 1}=0
\end{gathered}
$$

From (3c), (7a) and (7b), the rectifier transfer function during +ve half cycle of the input is

$$
G_{r 1}(S)=\frac{1}{1+S^{2} L_{r} C_{r}}
$$

In this follow-up, during the negative (-ve) half cycle of the input 

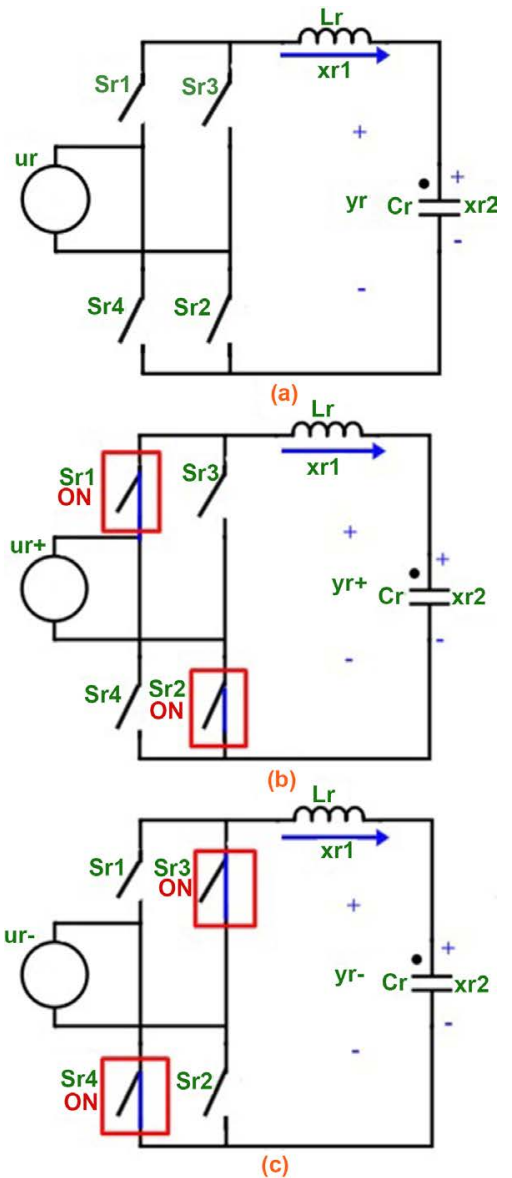

Figure 5. State averaging model of the rectifier circuit: (a) state space model, (b) equivalent model for positive input and (c) equivalent model for negative input.

$$
\begin{gathered}
\dot{x}_{r 1}=-\frac{1}{L_{r}} x_{r 2}-\frac{1}{L_{r}} u_{r-}, \dot{x}_{r 2}=\frac{1}{C_{r}} x_{r 1}, y_{r-}=x_{r 2} \\
A_{r 2}=\left[\begin{array}{cc}
0 & -\frac{1}{L_{r}} \\
\frac{1}{C_{r}} & 0
\end{array}\right] \\
B_{r 2}=\left[\begin{array}{c}
-\frac{1}{L_{r}} \\
0
\end{array}\right], C_{r 2}=\left[\begin{array}{ll}
0 & 1
\end{array}\right], D_{r 2}=0
\end{gathered}
$$

From (3c), (10a) and (10b), the rectifier transfer function during -ve half cycle of the input is

$$
G_{r 2}(S)=-\frac{1}{1+S^{2} L_{r} C_{r}}
$$

From circuit analysis and in accordance with (8) and (11), the resultant rectifier transfer function can be expressed as 


$$
G_{r}(S)=\left\|G_{r 1}(S)\right\|=\left\|G_{r 2}(S)\right\|=\frac{1}{1+S^{2} L_{r} C_{r}}
$$

\subsection{Derivation of $G_{c}(S)$}

Figure 6 presents the equivalent state space model of the boost converter circuit where $u_{c}$ is the input dc voltage (rectified + filtered), $y_{c}$ is the output voltage, $x_{c 1}$ and $x_{c 2}$ are the state variables. $S_{c 1}$ and $S_{c 2}$ are the state space models of $Q_{c}$ and $D_{c}$ respectively. During subinterval-1 or $d T_{p}$ interval, where $d$ is the duty ratio and $T_{p}$ is the switching period, $S_{c 1}$ is on (closed switch) and during subinterval-2 or $(1-d) T_{p}$ interval, $S_{c 2}$ is on (closed switch). During the $d T_{p}$ interval,

$$
\begin{gathered}
\dot{x}_{c 1}=\frac{1}{L_{c}} u_{c}, \dot{x}_{c 2}=-\frac{1}{R_{c} C_{c}} x_{c 2}, y_{c}=x_{c 2} \\
A_{c 1}=\left[\begin{array}{cc}
0 & 0 \\
0 & -\frac{1}{R_{c} C_{c}}
\end{array}\right] \\
B_{c 1}=\left[\begin{array}{c}
\frac{1}{L_{c}} \\
0
\end{array}\right], C_{c 1}=\left[\begin{array}{ll}
0 & 1
\end{array}\right], D_{c 1}=0
\end{gathered}
$$

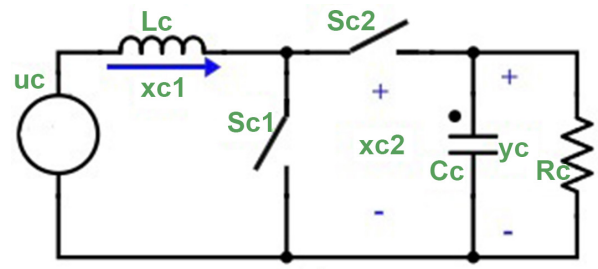

(a)

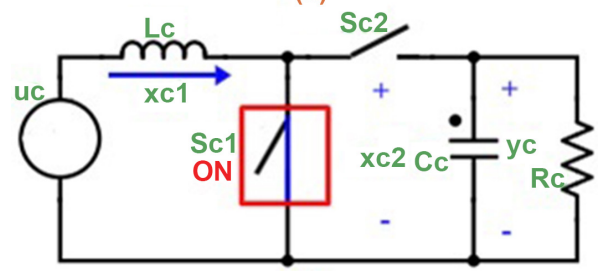

(b)

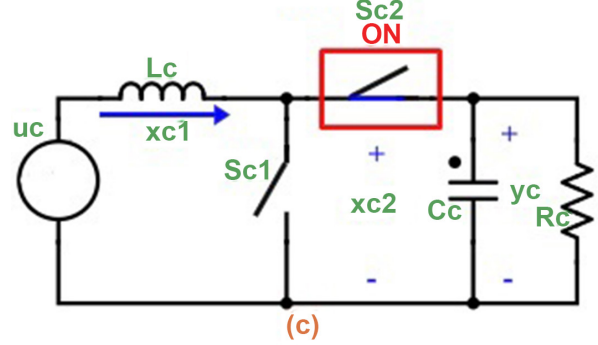

Figure 6. State averaging model of the boost converter; (a) state space model: (b) equivalent model during $d T_{p}$ interval or subinterval-1; (c) equivalent model during $(1-d) T_{p}$ interval or subinterval-2. 
During the $(1-d) T_{p}$ interval,

$$
\begin{gathered}
\dot{x}_{c 1}=-\frac{1}{L_{c}} x_{c 2}+\frac{1}{L_{c}} u_{c}, \dot{x}_{c 2}=\frac{1}{C_{c}} x_{c 1}-\frac{1}{R_{c} C_{c}} x_{c 2}, y_{c}=x_{c 2} \\
A_{c 2}=\left[\begin{array}{cc}
0 & -\frac{1}{L_{c}} \\
\frac{1}{C_{c}} & -\frac{1}{R_{c} C_{c}}
\end{array}\right] \\
B_{c 2}=\left[\begin{array}{c}
\frac{1}{L_{c}} \\
0
\end{array}\right], C_{c 2}=\left[\begin{array}{ll}
0 & 1
\end{array}\right], D_{c 2}=0
\end{gathered}
$$

In cumulative form,

$$
\begin{aligned}
& A_{c}=d A_{c 1}+(1-d) A_{c 2} \\
& B_{c}=d B_{c 1}+(1-d) B_{c 2}
\end{aligned}
$$

Therefore

$$
\begin{gathered}
A_{c}=\left[\begin{array}{cc}
0 & -\frac{1-d}{L_{c}} \\
\frac{1-d}{C_{c}} & -\frac{1}{R_{c} C_{c}}
\end{array}\right] \\
B_{c}=\left[\begin{array}{c}
\frac{1}{L_{c}} \\
0
\end{array}\right], C_{c}=\left[\begin{array}{ll}
0 & 1
\end{array}\right], D_{c}=0
\end{gathered}
$$

From (3c), (17a) and (17b), the converter transfer function can be expressed as

$$
G_{c}(S)=\frac{1-d}{S^{2} L_{c} C_{c}+\frac{S L_{c}}{R_{c}}+(1-d)^{2}}
$$

\subsection{Derivation of $G(S)$}

According to (4), (12) and (19), the overall charging system transfer function can be expressed as

$$
G(S)=\left[\frac{1}{1+S^{2} L_{r} C_{r}}\right]\left[\frac{1-d}{S^{2} L_{c} C_{c}+\frac{S L_{c}}{R_{c}}+(1-d)^{2}}\right]
$$

From (20), the steady state charging system transfer function yields to

$$
G_{s s}=G(0)=\frac{1}{1-d}
$$

(21) is similar to the dc voltage gain of a generic boost converter.

\section{Equivalent Switching Converter Model of the Proposed Inverter Circuit}

This section presents the derivation and analysis of an equivalent switching 
converter model of the proposed 4-switch push-pull inverter circuit. There are two switch legs-leg1: $Q_{i 1}-Q_{i 2}$ and leg2: $Q_{i 3}-Q_{i 4}$ in the inverter circuit. For effective power transformation, $Q_{i 1}$ and $Q_{i 2}$ are switched-on simultaneously whereas $Q_{i 3}$ and $Q_{i 4}$ are switched-on simultaneously. Inverter switch legs-leg1 and leg2 are controlled by two alternating PWM pulses. Each of inverter 4-switches is a power MOSFET with an anti-parallel diode (body diode) constituting a current-bidirectional switch. Figure 7 presents a simplified model of the inverter switch in which a leg consisting of two switches is represented by a single pole single throw (SPST) switch model. Considering device losses, a closed switch is represented by an on-state resistance $R_{o n}$. Figure 8 shows the equivalent switching converter model of the push-pull inverter circuit. Here $S_{i 1}$ presents the switch leg: $Q_{i 3}-Q_{i 4}$ and $S_{i 2}$ presents the switch leg: $Q_{i 1}-Q_{i 2}$. During subinterval-1 or $d T_{s}$ interval, where $d$ is the duty ratio and $T_{s}$ is the switching period, $S_{i 1}$ is on (closed switch) and during subinterval-2 or $(1-d) T_{s}$ interval, $S_{i 2}$ is on (closed switch). The circuit modeling approach assumes small ripple approximation. During $d T_{s}$ interval, the average inductor voltage is

$$
V_{L o}=n V_{i}-n I_{i} R_{o n}-V_{o}
$$

During $(1-d) T_{s}$ interval, the average inductor voltage is

$$
V_{L o}=-n V_{i}+n I_{i} R_{o n}-V_{o}
$$

According to inductor volt-second balance theory,

$$
\begin{gathered}
0=\left[n V_{i}-n I_{i} R_{o n}-V_{o}\right][d]+\left[-n V_{i}+n I_{i} R_{o n}-V_{o}\right][1-d] \\
V_{o}=n d\left[V_{i}-I_{i} R_{o n}\right]
\end{gathered}
$$

hence the voltage gain of the circuit is

$$
G_{v}=\frac{V_{o}}{V_{i}}=n d\left[1-R_{o n} \frac{I_{i}}{V_{i}}\right]=n d\left[1-\frac{R_{o n}}{R_{i}}\right]
$$

here input port resistance $R_{i}=\frac{V_{i}}{I_{i}}$. In case of lossless $\left(R_{o n} \approx 0\right)$ switching devices,

$$
G_{v}=\frac{V_{o}}{V_{i}}=n d
$$

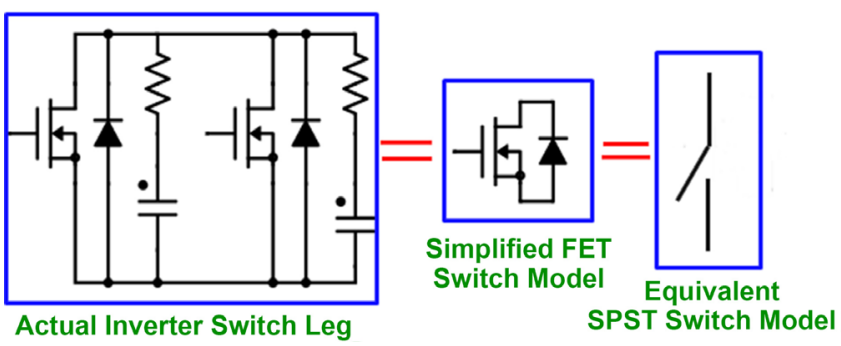

Figure 7. Simplified model of the switch used in the proposed power inverter circuit. 

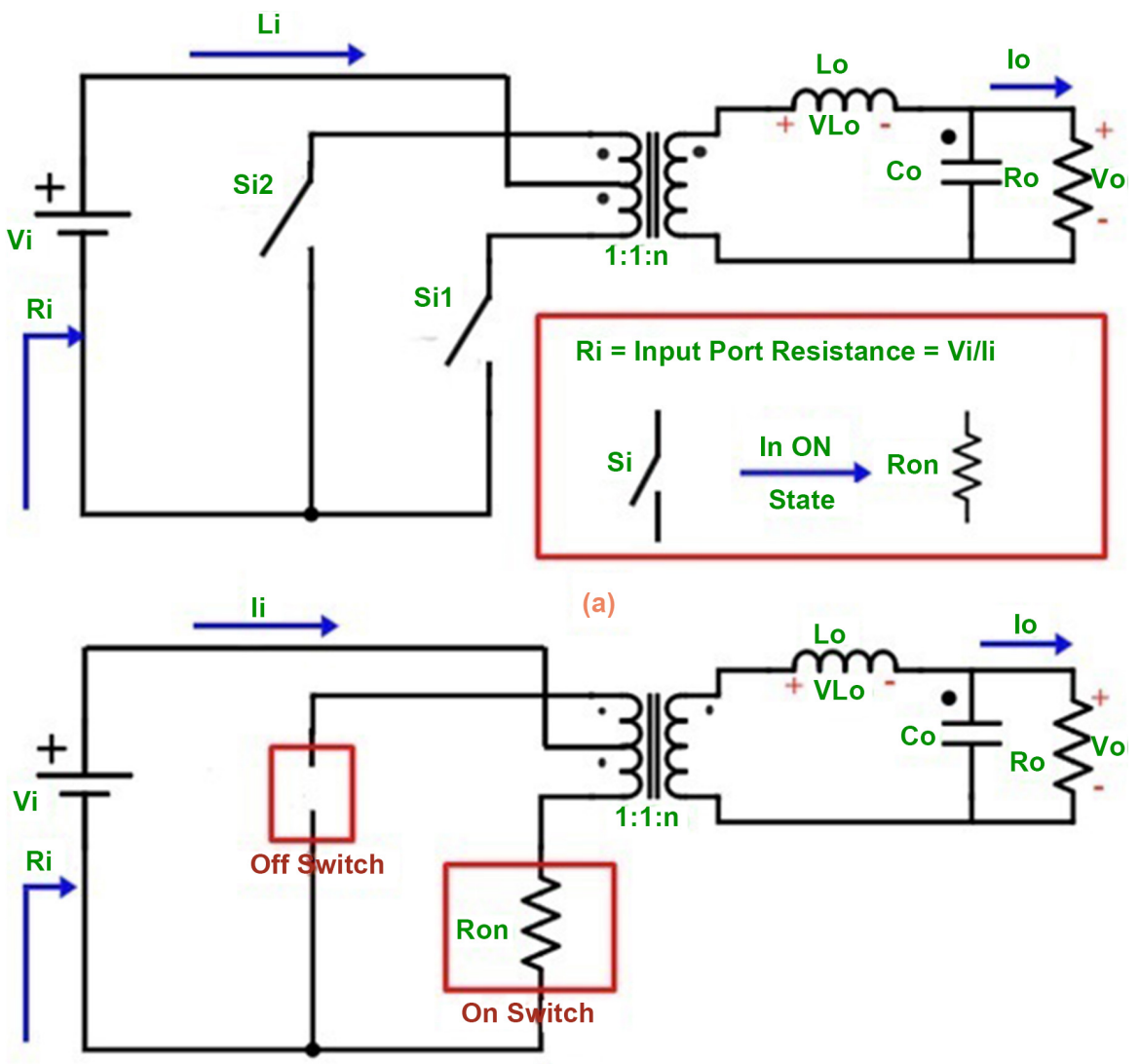

(b)

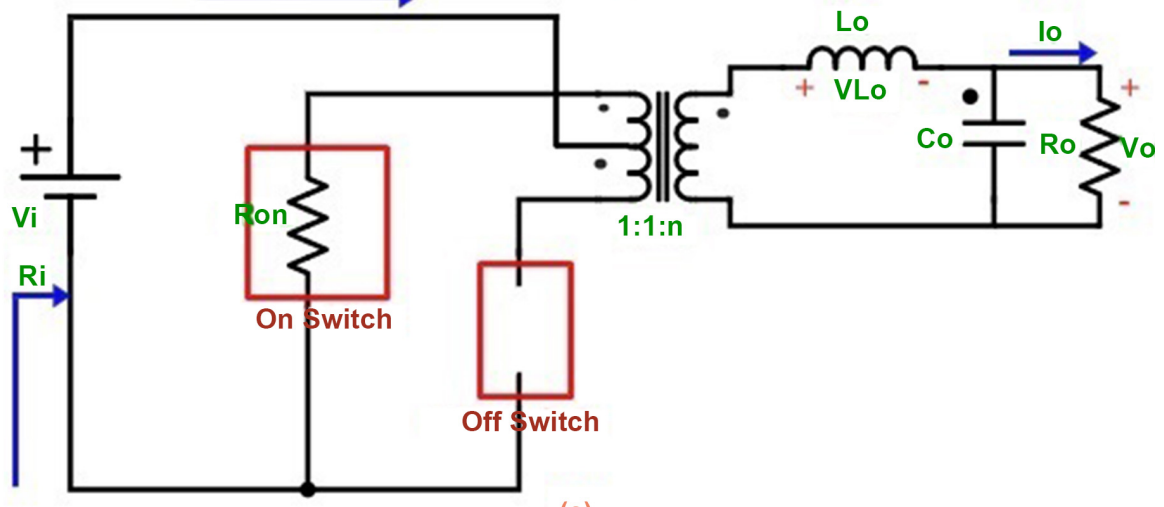

(c)

Figure 8. Switching converter model of the power inverter circuit: (a) switching converter model; (b) equivalent model during $d T_{s}$ interval or subinterval-1; (c) equivalent model during $(1-d) T_{s}$ interval or subinterval-2.

By definition the power efficiency of the inverter is

$$
\begin{gathered}
\eta_{i}=\frac{P_{o}}{P_{i}} \times 100 \%=\frac{\frac{V_{o}^{2}}{R_{o}}}{V_{i} R_{i}} \times 100 \% \\
\eta_{i}=\frac{n^{2} d^{2}\left[V_{i}-I_{i} R_{o n}\right]^{2}}{R_{o} V_{i} I_{i}} \times 100 \%
\end{gathered}
$$


here $P_{i}$ and $P_{o}$ are the input and output power of the circuit respectively. In case of lossless $\left(R_{o n} \approx 0\right)$ switching devices,

$$
\eta_{i}=\frac{n^{2} d^{2}}{R_{o}} \frac{V_{i}}{I_{i}} \times 100 \%=n^{2} d^{2} \frac{R_{i}}{R_{o}} \times 100 \%
$$

From (25) and (28) it can be concluded that

$$
G_{v}, \eta_{i}=f(n, d)
$$

(29) shows that the inverter voltage gain and efficiency are functions of the transformer turns ratio and switching signal duty ratio.

\section{Simulation Results}

The proposed 4-switch push-pull inverter based emergency back-up power supply with grid-interfaced battery charging circuit is simulated in PLECS(version 4.2) for an R-L load of $R=500 \Omega$ and $L=27 \mathrm{mH}$ with a maximum power consumption of nearly $104 \mathrm{~W}$. The battery is a $12 \mathrm{~V}$ voltage source and the switching relays are the relay models available in PLECS library. However, the switching PWM signals are generated independently by symmetrical PWM blocks of PLECS.

Table 1 presents the circuit components' specifications of the system. The components' notations follow the manner as presented in Figure 1. Table 2 presents the simulation outcomes of harmonic analysis of the mains line current, inverter output voltage and load current. Figures 9-13 present the simulated waveforms of the system components. However, in Figures 9-12 the $\mathrm{x}$-axis represents the simulation time in $\mathrm{s}$ whereas in Figure 13 the $\mathrm{x}$-axis contains the frequency values in $\mathrm{Hz}$. Table 3 presents the performance evaluation of the proposed system in terms of sending-end power factor, mains current THD, inverter output voltage THD and load current THD. By definition, the sending-end power factor is

$$
P F_{s}=\frac{P_{R}}{S_{A}}=\frac{V_{s} I_{s} \cos \phi}{V_{s} I_{s}}=\cos \phi
$$

here $P_{R}$ is the real power (w), $S_{A}$ is the apparent power (VA), $\phi$ is the angle between voltage, $V_{s}$ and current $I_{s}$. By definition, current THD (\%) and voltage THD (\%) are

$$
\begin{gathered}
I_{T H D}=\frac{\sqrt{I_{2}^{2}+I_{3}^{2}+I_{4}^{2}+I_{5}^{2}+I_{6}^{2}+\cdots}}{I_{1}} \times 100 \% \\
V_{T H D}=\frac{\sqrt{V_{2}^{2}+V_{3}^{2}+V_{4}^{2}+V_{5}^{2}+V_{6}^{2}+\cdots}}{V_{1}} \times 100 \%
\end{gathered}
$$

Any power quantity can be represented by $H(=V$ and $I)$. Here $H_{1}$ is the fundamental or base frequency component, $H_{2}, H_{3}, H_{4}, H_{5}$ etc are the 2nd, 3rd, 4th, 5th etc. order harmonic components respectively. Table 3 shows that in simulation, the sending-end power factor and mains current THD of the system are around $0.96 \%$ and $21 \%$ respectively which are considered appropriate for a 
Table 1. Specifications of the system circuitries.

\begin{tabular}{|c|c|}
\hline Components' Notations & Specifications \\
\hline$T_{x 1}$ & $\begin{array}{l}230-12 \mathrm{~V}, 300 \mathrm{~W}, 50 \mathrm{~Hz} \text { iron core step-down transformer with a turns } \\
\text { ratio of } N_{1}: N_{2}=38: 2\end{array}$ \\
\hline 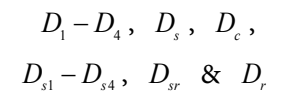 & Power diodes \\
\hline$L_{r}$ & $0.1 \mathrm{mH}$, rectifier output filter inductance \\
\hline$C_{r}$ & $500 \mu \mathrm{F}$, rectifier output filter capacitance ( $25 \mathrm{~V}$ electrolytic capacitor) \\
\hline$L_{c}$ & $0.95 \mathrm{mH}$, boost converter input inductance \\
\hline$C_{c}$ & $47 \mu \mathrm{F}$, boost converter output capacitance ( $50 \mathrm{~V}$ electrolytic capacitor) \\
\hline$Q_{c}, Q_{i 1}-Q_{i 4} \& Q_{r}$ & $\begin{array}{l}\text { N-channel enhancement type MOSFET with an absolute maximum } \\
\text { on-resistance, } R_{o n}=17.5 \mathrm{~m} \Omega \text { and maximum drain current, } I_{D}=49 \mathrm{~A}\end{array}$ \\
\hline Battery & $12 \mathrm{~V}$ (rated nominal voltage), $7.5 \mathrm{~A}-\mathrm{h}$ (capacity) and $9 \mathrm{~V}$ (cut-off voltage) \\
\hline$R_{s 1}-R_{s 4}$ & $225 \Omega$, snubber resistance \\
\hline$C_{s 1}-C_{s 4} \& C_{s r}$ & $10 \mathrm{nF}$, snubber capacitance \\
\hline$T_{x 2}$ & $\begin{array}{l}12-230 \mathrm{~V}, 400 \mathrm{~W}, 50 \mathrm{~Hz} \text { iron core step-up transformer with a } \\
\text { center-tapped primary side and a turns ratio of } n_{1}: n_{2}: n_{3}=2: 2: 38\end{array}$ \\
\hline$L_{o}$ & $21.2 \mathrm{mH}$, inverter output filter inductance \\
\hline$C_{o}$ & $470 \mu \mathrm{F}$, inverter output filter capacitance ( $250 \mathrm{~V}$ electrolytic capacitor) \\
\hline A & Op-amp with the biasing voltage of $V_{+}=12 \mathrm{~V}$ and $V_{-}=0 \mathrm{~V}$ \\
\hline$R_{r 1} \& R_{r 2}$ & $\begin{array}{l}1 \mathrm{k} \Omega \text { and } 12 \mathrm{k} \Omega \text { respectively, resistances in the input terminal of the } \\
\text { battery charge controller circuit }\end{array}$ \\
\hline$V_{d d}$ & $12 \mathrm{~V}$, biasing voltage of the relay switching circuit \\
\hline $\mathrm{C}, \mathrm{NO} \& \mathrm{NC}$ & $\begin{array}{l}\text { Common, normally open and normally closed terminals of a } 250 \mathrm{~V}, 20 \mathrm{~A} \text {, } \\
\text { SPDT electromechanical relay }\end{array}$ \\
\hline Transfer Switch & $250 \mathrm{~V}, 30 \mathrm{~A}, 3 \mathrm{~ms}$ (transfer rate) electromechanical relay \\
\hline Loads & $\begin{array}{l}\text { In simulation, an R-L load of } R=500 \Omega \text { and } L=27 \mathrm{mH} \text { with a } \\
\text { maximum power consumption of } 103.59 \mathrm{~W}\end{array}$ \\
\hline
\end{tabular}

Table 2. Simulated data of harmonic analysis.

\begin{tabular}{cccc}
\hline $\begin{array}{c}\text { Harmonic } \\
\text { Order, } n\end{array}$ & $\begin{array}{r}\text { Mains Harmonic Current } \\
\text { Content, } I_{n, m}(\mathrm{~A})\end{array}$ & $\begin{array}{c}\text { Inverter Output } \\
\text { Harmonic Voltage } \\
\text { Content, } V_{n, l}(\mathrm{~V})\end{array}$ & $\begin{array}{c}\text { Load Harmonic Current } \\
\text { Content, } I_{n, l} \quad(\mathrm{~A})\end{array}$ \\
\hline 1 & 20.2184 & 228.361 & 0.45473 \\
3 & 3.97007 & 19.3039 & 0.0385546 \\
5 & 1.25227 & 17.5455 & 0.0349619 \\
7 & 0.367276 & 14.1336 & 0.0280666 \\
9 & 0.476162 & 11.1722 & 0.0220854 \\
11 & 0.337621 & 9.68919 & 0.0190475 \\
13 & 0.140560 & 8.78997 & 0.0171669 \\
even & 0 & 0 & 0 \\
\hline
\end{tabular}




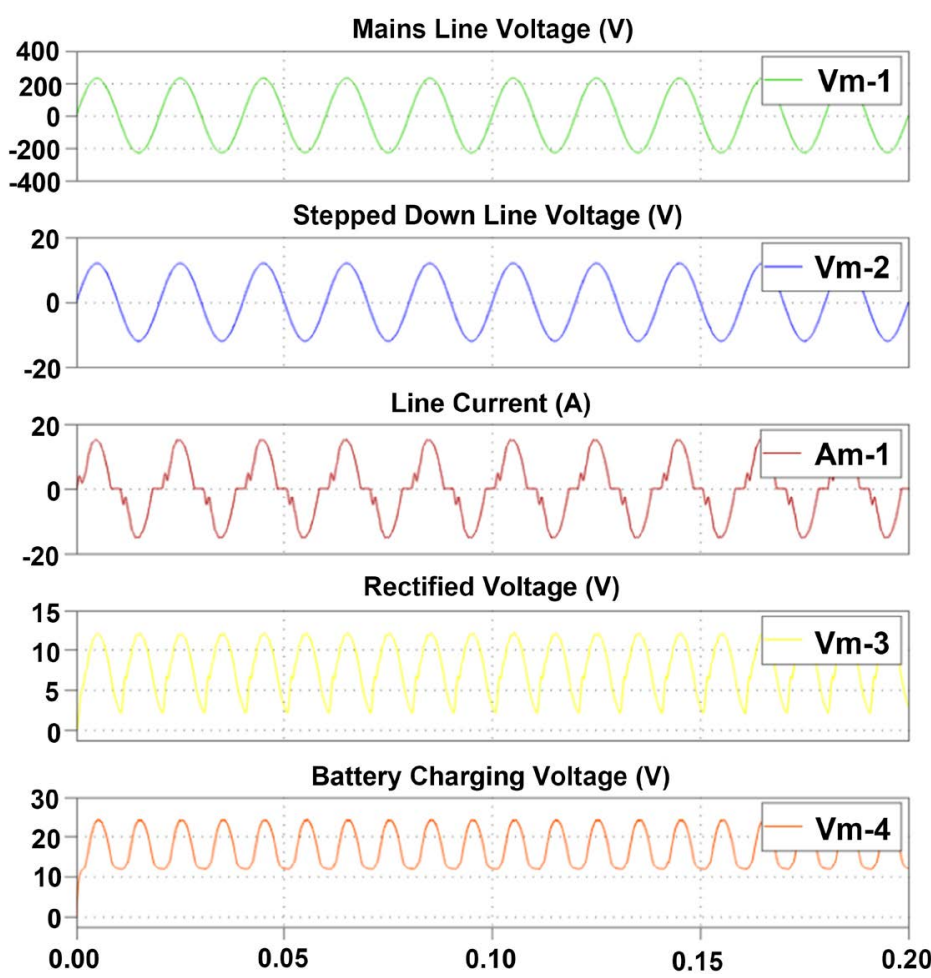

Figure 9. Simulated waveforms of the mains line voltage, stepped-down line voltage, mains current, rectified voltage and battery charging voltage $[\mathrm{x}$-axis is scaled in time $(\mathrm{s})]$.
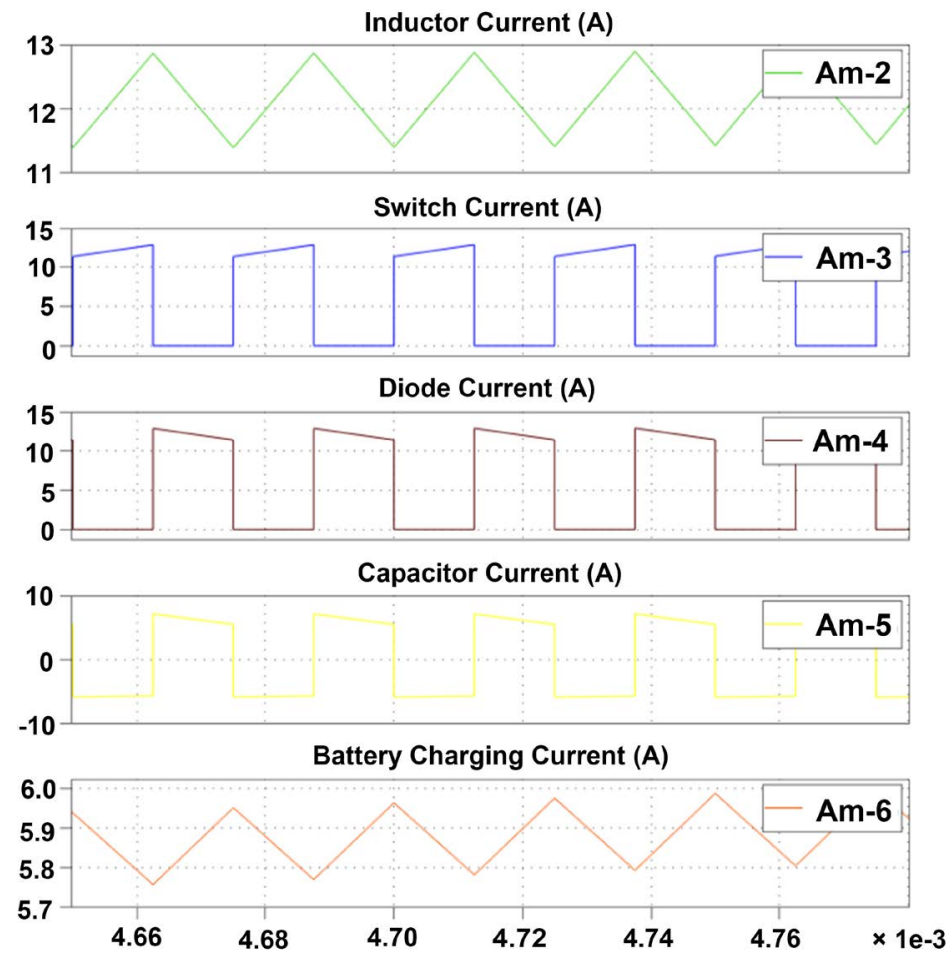

Figure 10. Simulated current waveforms across the inductor, switch, diode, capacitor and output port of the boost converter [x-axis is scaled in time (s)]. 

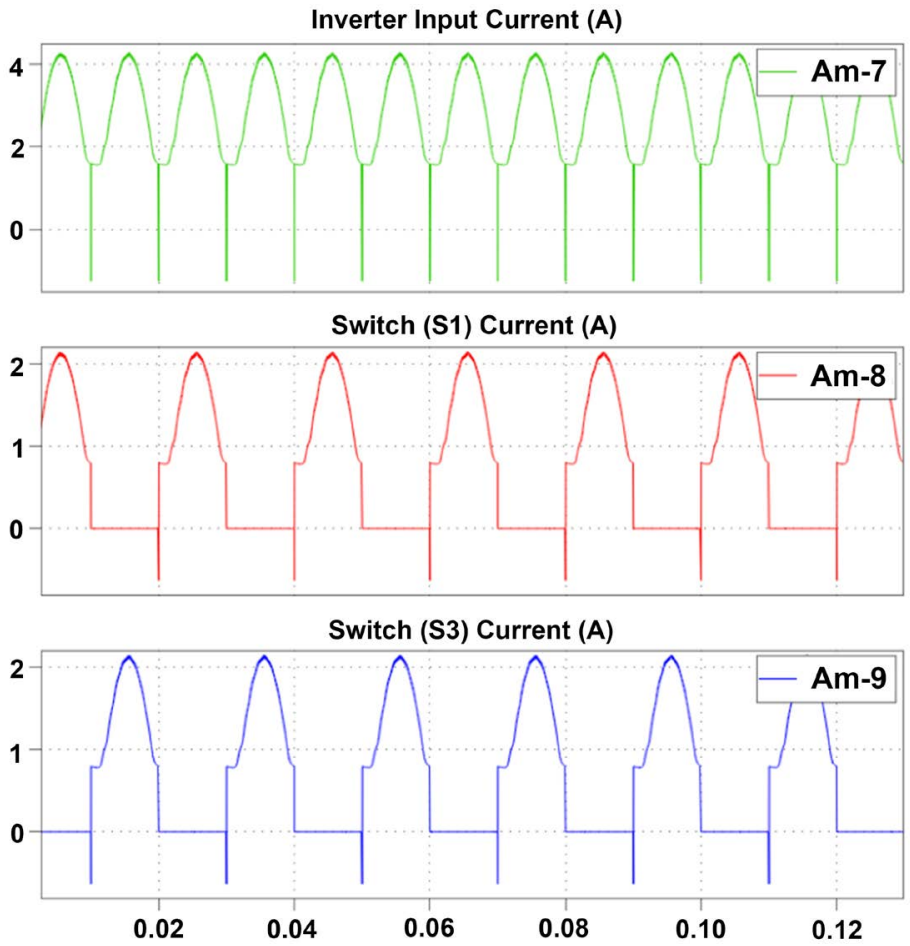

Figure 11. Simulated waveforms of inverter input current, the current through switch $S 1\left(Q_{i 3}\right)$ and current through switch $S 3\left(Q_{i 1}\right)$ for an R-L load of $R=500 \Omega$ and $L=27 \mathrm{mH}$ [x-axis is scaled in time (s)].

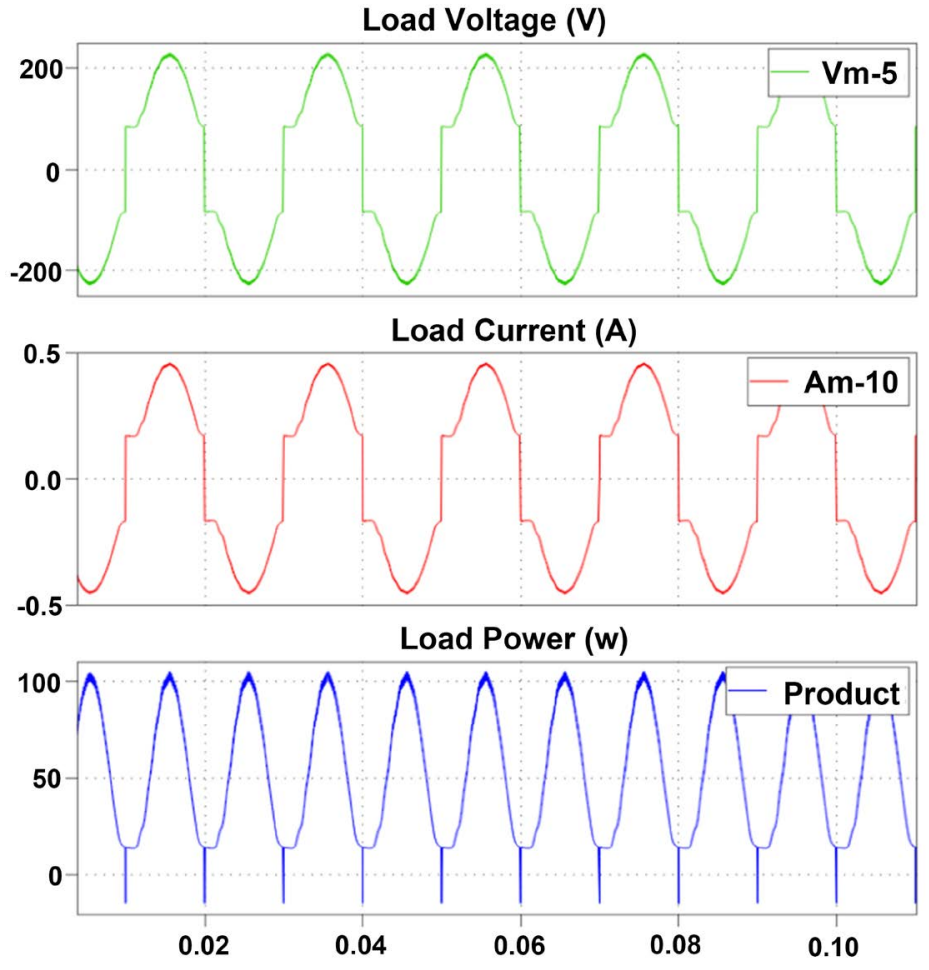

Figure 12. Simulated waveforms of the load voltage, load current and consumed power of the inverter for an R-L load of $R=500 \Omega$ and $L=27 \mathrm{mH} \quad$ [x-axis is scaled in time (s)]. 


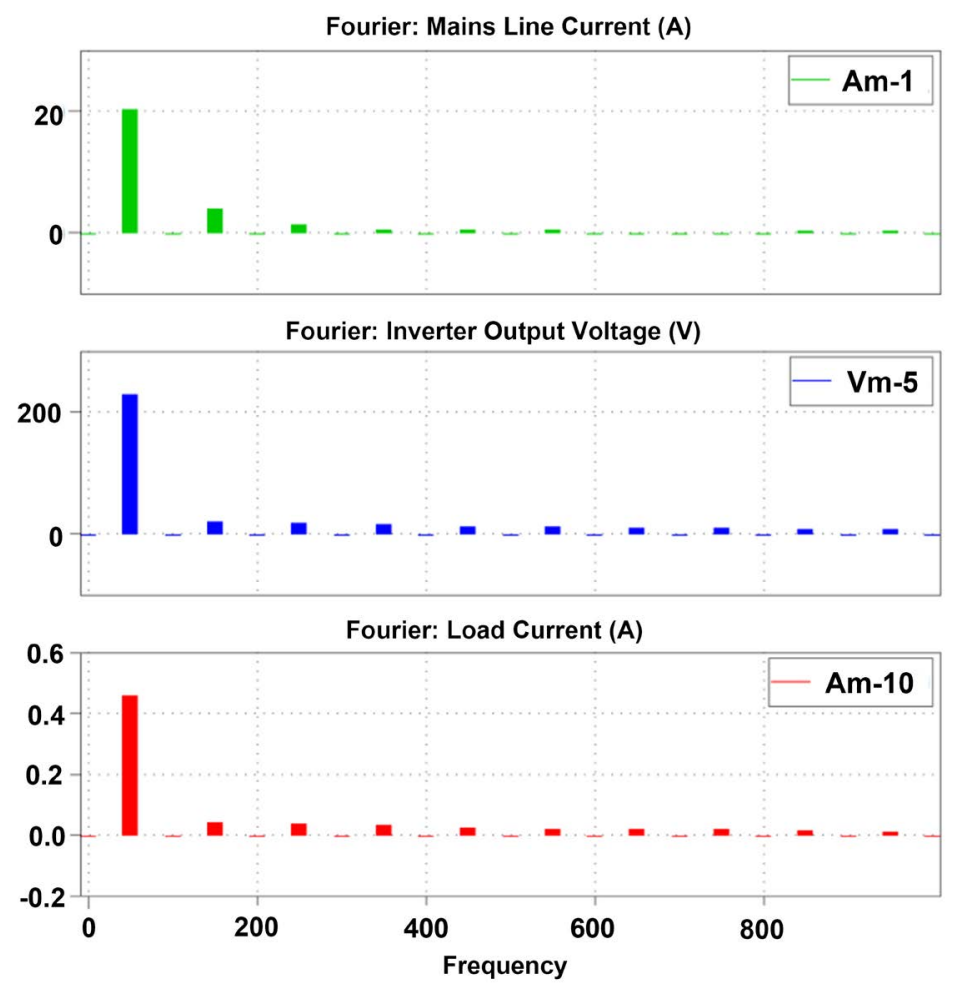

Figure 13. Simulated Fourier spectra of the mains current, inverter output voltage and output current for a load of $R=500 \Omega$ and $L=27 \mathrm{mH}$ [x-axis is scaled in frequency $(\mathrm{Hz})]$.

Table 3. Simulated data of the performance parameters for a maximum load power consumption of $103.59 \mathrm{~W}$.

\begin{tabular}{cccc}
\hline $\begin{array}{c}\text { Sending-End Power } \\
\text { Factor, } P F_{s}\end{array}$ & $\begin{array}{c}\text { Mains Current THD, } \\
I_{\text {mTHD }} \quad(\%)\end{array}$ & $\begin{array}{c}\text { Inverter Output } \\
\text { Voltage THD, } V_{\text {ITHD }} \\
(\%)\end{array}$ & $\begin{array}{c}\text { Load Current THD, } I_{\text {ITHD }} \\
(\%)\end{array}$ \\
\hline 0.9639 & 20.8818 & 15.0183 & 14.9827 \\
\hline
\end{tabular}

rectifier-link dc boost converter with PWM switching control application. In simulation, for an R-L load with an approximated maximum power consumption of $104 \mathrm{~W}$, the load voltage THD and load current THD values are about 15\% which are considerably low and acceptable for an efficient power supply system.

\section{Conclusions}

In this paper, design of a grid-integrated emergency back-up power supply for medium power utility applications is articulated. A 4-switch push-pull inverter circuit topology is designed and simulated, which generates modified square wave voltage signals at the grid frequency $(50 \mathrm{~Hz})$. The battery is charged by a rectifier-fed PWM boost derived charging circuit. The instantaneous transfer switching from the grid to the customized power supply system is substantiated by a changeover relay. An SPDT relay switching circuit forms a battery charge controller to provide over-voltage and over-charge protection. The switching 
converters are controlled by high frequency $(40 \mathrm{kHz})$ and mains line frequency $(50 \mathrm{~Hz})$ PWM signals respectively. However, state averaging and switching converter models of the charging circuit and power inverter are derived. The proposed design is simulated in PLECS.

The emergency back-up power supply provides an efficacious solution to support electrical loads during a grid power failure. The grid-interfaced feature substantiates continual power transfer to the connected utility loads without any interruption. The simulation performance confirms the efficiency of the presented design. However, the design is considered to be reasonable for frequent consumer applications. The future scope of the presented work is to develop a laboratory prototype to experiment its performance for practical implementation. However, a more compact and high power sine wave generating power supply circuit with feedback control feature can improve the performance of the proposed system.

\section{Acknowledgements}

This work is supported by Department of Electrical and Electronics Engineering, Daffodil International University, Dhaka, Bangladesh.

\section{Conflicts of Interest}

The authors declare no conflicts of interest regarding the publication of this paper.

\section{References}

[1] Choi, J. and Kang, F. (2015) Seven-Level PWM Inverter Employing Series-Connected Capacitors Paralleled to a Single DC Voltage Source. IEEE Transactions on Industrial Electronics, 62, 3448-3459.

[2] Botterón, F., Carballo, R.E., Núñez, R.O., Quintana, A.P. and Fernández, G.A. (2013) High Reliability and Performance PWM Inverter for Standalone Microgrids. IEEE Latin America Transactions, 11, 505-511. https://doi.org/10.1109/TLA.2013.6502853

[3] Pan, C., Lai, C. and Juan, Y. (2010) Output Current Ripple-Free PWM Inverters. IEEE Transactions on Circuits and Systems II: Express Briefs, 57, 823-827. https://doi.org/10.1109/TCSII.2010.2058596

[4] Mezaroba, M., Martins, D.C. and Barbi, I. (2007) A ZVS PWM Half-Bridge Voltage Source Inverter with Active Clamping. IEEE Transactions on Industrial Electronics, 54, 2665-2672. https://doi.org/10.1109/TIE.2007.901361

[5] Chen, D., Qiu, Y., Chen, Y. and He, Y. (2017) Nonlinear PWM-Controlled Single-Phase Boost Mode Grid-Connected Photovoltaic Inverter with Limited Storage Inductance Current. IEEE Transactions on Power Electronics, 32, 2717-2727. https://doi.org/10.1109/TPEL.2016.2571725

[6] Kim, Y., Shin, S., Lee, J., Jung, Y. and Won, C. (2014) Soft-Switching Current-Fed Push-Pull Converter for 250-W AC Module Applications. IEEE Transactions on Power Electronics, 29, 863-872. https://doi.org/10.1109/TPEL.2013.2258942

[7] Reznikov, B., Srndovic, M., Familiant, Y.L., Grandi, G. and Ruderman, A. (2016) Simple Time Averaging Current Quality Evaluation of a Single-Phase Multilevel 
PWM Inverter. IEEE Transactions on Industrial Electronics, 63, 3605-3615. https://doi.org/10.1109/TIE.2016.2541078

[8] Lee, J., Kwak, R. and Lee, K. (2018) Novel Discontinuous PWM Method for a Single-Phase Three-Level Neutral Point Clamped Inverter with Efficiency Improvement and Harmonic Reduction. IEEE Transactions on Power Electronics, 33, 9253-9266. https://doi.org/10.1109/TPEL.2018.2794547

[9] Ye, Y., Xu, G., Wu, Y. and Zhao, Q. (2018) Optimized Switching Repetitive Control of CVCF PWM Inverters. IEEE Transactions on Power Electronics, 33, 6238-6247. https://doi.org/10.1109/TPEL.2017.2740565

[10] Chauprade, R. (1977) Inverters for Uninterruptible Power Supplies. IEEE Transactions on Industry Applications, IA-13, 281-297. https://doi.org/10.1109/TIA.1977.4503410

[11] Rymarski, Z. and Bernacki, K. (2016) Different Approaches to Modelling Single-Phase Voltage Source Inverters for Uninterruptible Power Supply Systems. IET Power Electronics, 9, 1513-1520. https://doi.org/10.1049/iet-pel.2015.0142

[12] Bernacki, K. and Rymarski, Z. (2015) Electromagnetic Compatibility of Voltage Source Inverters for Uninterruptible Power Supply System Depending on the Pulse-Width Modulation Scheme. IET Power Electronics, 8, 1026-1034. https://doi.org/10.1049/iet-pel.2014.0637

[13] Chen, J. and Chu, C. (1995) Combination Voltage-Controlled and Current-Controlled PWM Inverters for UPS Parallel Operation. IEEE Transactions on Power Electronics, 10, 547-558. https://doi.org/10.1109/63.406842

[14] Komurcugil, H. (2015) Improved Passivity-Based Control Method and Its Robustness Analysis for Single-Phase Uninterruptible Power Supply Inverters. IET Power Electronics, 8, 1558-1570. https://doi.org/10.1049/iet-pel.2014.0706

[15] Shahparasti, M., Yazdian, A., Mohamadian, M., Larijani, A.S. and Fatemi, A. (2012) Parallel Uninterruptible Power Supplies Based on Z-Source Inverters. IET Power Electronics, 5, 1359-1366. https://doi.org/10.1049/iet-pel.2011.0403

[16] Chowdhury, D., Hossain, M.F., Miah, M.S., Hossain, M.M., Sheikh, M.N.U., Rahman, M.M. and Hasan, M.M. (2018) Design and Implementation of a Switching Converters Based Power System for Regions Victim to Frequent Power Outage. SoutheastCon 2018 Proceedings, St. Petersburg, FL, 19-22 April 2018, 1-6. https://doi.org/10.1109/SECON.2018.8478910

[17] Nie, Z. and Schofield, N. (2017) Analysis and Comparison of Power Electronic Converters for Conventional and Toroidal Switched Reluctance Machines. Energy and Power Engineering, 9, 241-259. https://doi.org/10.4236/epe.2017.94017

[18] Barsoum, N.N. (2010) Implementation of a Higher Quality dc Power Converter. Journal of Electromagnetic Analysis and Applications, 2, 82-90. https://doi.org/10.4236/jemaa.2010.22012

[19] Zhang, J., Li, L. and Liu, C. (2017) A Novel Method of Auxiliary Power Supply Used in Wide-Range High Voltage Input DC-DC Converter. Energy and Power Engineering, 9, 703-712. https://doi.org/10.4236/epe.2017.94B076

[20] Sharif, S.A., Harb, A., Hu, H. and Batarseh, I. (2014) An Experimental Simulation of a Design Three-Port DC-DC Converter. Circuits and Systems, 5, 238-251. https://doi.org/10.4236/cs.2014.510026

[21] Arunkumar, N., Sivakumaran, T.S., Ramashkumar, K. and Shenbagalakshmi, R. (2016) Analysis, Modeling and Simulation of State Feedback Control for Positive Output Super Lift Luo Converter. Circuits and Systems, 7, 3971-3983. https://doi.org/10.4236/cs.2016.711329 